\title{
26447 - SERUM ERYTHROPOIETIN LEVELS INCREASE AFTER CORONARY ARTERY BYPASS SURGERY AND ARE ASSOCIATED WITH NEUROLOGICAL OUTCOME AT DISCHARGE FROM HOSPITAL.
}

\author{
Greg Haljan MD, Ainslie M Sutherland, BSc; John M Murkin, MD; Keith R \\ Walley, St. Paul's Hospital And UBC, Vancouver, BC, Canada
}

INTRODUCTION: Coronary artery bypass surgery (CABG) is complicated by neurocognitive dysfuntion (NCD) in 50-75\% of patients at discharge, 20-50\% at 6 weeks and $42 \%$ at five years. Erythropoietin (Epo) is produced by a variety of tissues in response to cellular ischemia and injury. We asked if CABG surgery was a stimulus to Epo production by measuring serum Epo levels at 0, 4, 12 and 24 hours, and asked if NCD was associated with serum Epo.

METHODS: Serum was drawn in 25 first-time CABG patients who had NCD testing preoperatively, at discharge and at 3 months. NCD was defined as a $20 \%$ decline from baseline in $20 \%$ of tests. Serum Epo was quantified by ELISA kit from Stem Cell Technologies.

RESULTS: All patients were male, mean age 59 (range 42-82). 4 patients (16\%) underwent off-pump CABG (OP-CABG). A history of MI was present in $44 \%$ patients, heart failure in $16 \%$, atrial fibrillation in $16 \%$, hypertension in $92 \%$, diabetes in $40 \%$, dyslipidemia in $80 \%$, family history of MI in $40 \%$, smoking in $44 \%$, chronic obstructive pulmonary disease in $16 \%$, and renal dysfunction (Crt $>150 \mathrm{mg} / \mathrm{dl}$ ) in $12 \%$. No patients had a history of dialysis, Epo injections or a neurologic diagnosis. Mean pump time was $92 \mathrm{~min}$ (SD 27) and mean cross-clamp time was $66 \mathrm{~min}$ (SD 24). Median ICU LOS was 24 hours (IQR 24-42) and median Hospital LOS was 6 days (IQR 4-7). 31\% of patients required a transfusion (median 2 units PRBC). 31\% developed post-op afib. Mean hemoglobin (Hgb) post-op was 114 (SD 12.2). 60\% (15/25) of patients suffered NCD at discharge and 52\% (13/25) suffered NCD at 3 months. Four patients (3/10 without NCD and 1/15 with NCD) were missing $24 \mathrm{~h}$ blood. Mean Epo levels for all patients rose significantly from $11.9 \mathrm{pg} / \mathrm{ml}(\mathrm{SD} 8.0 \mathrm{pg} / \mathrm{ml})$ to $18.8 \mathrm{pg} / \mathrm{ml}(\mathrm{SD} 14.7)$ at $12 \mathrm{~h}(\mathrm{p}<0.01)$ and $32.1 \mathrm{pg} / \mathrm{ml}(\mathrm{SD} 21)$ at $24 \mathrm{~h}(\mathrm{p}<0.01)$. Epo at any time point was not associated with on- vs off-pump CABG, nor with cross clamp time and pump time, nor with pre-op or post-op Hgb levels, nor transfusion incidence. Low pre-op Epo was associated with NCD at discharge (9.2 pg/ml (SD 5.9) vs $15.9 \mathrm{pg} / \mathrm{ml}$ (SD 9.3), $\mathrm{p}=0.03)$. Mean increase in Epo at $12 \mathrm{~h}$ in patients with NCD at discharge vs non-NCD was $11.2 \mathrm{pg} / \mathrm{ml}$ (SD 14.7) vs 0.48 (SD 13.2), $\mathrm{p}=0.08$, and at 24h, $24.9 \mathrm{pg} / \mathrm{ml}$ (SD 22.3) vs $13.8 \mathrm{pg} / \mathrm{ml}$ (SD 17.0), $\mathrm{p}=0.26$. No significant differences were found in Epo levels between 3 month NCD and non-NCD patients.

CONCLUSIONS: Serum Epo levels rose significantly following CABG surgery, suggesting that the surgery results in significant hypoxia and cellular injury. Low pre-op serum Epo was associated with NCD at discharge, but not at follow-up. A trend to a greater increase in Epo was observed in patients with NCD at discharge. Off pump surgery did not appear to alter the Epo response. 